\title{
Rapunzel syndrome: an uncommon tale of a long hairy tail - case report and review of literature
}

\author{
Dinesh Manchikanti, Manisha Aggarwal, Shaji Thomas*, Ashish Arsia, \\ Rahul Pusuluri, Sanjay Kumar
}

Department of Surgery, Lady Hardinge Medical College and Dr RML Hospital, New Delhi, India

Received: 25 September 2021

Accepted: 19 October 2021

*Correspondence:

Dr. Shaji Thomas,

E-mail: drshajithomas@yahoo.com

Copyright: ( ) the author(s), publisher and licensee Medip Academy. This is an open-access article distributed under the terms of the Creative Commons Attribution Non-Commercial License, which permits unrestricted non-commercial use, distribution, and reproduction in any medium, provided the original work is properly cited.

\begin{abstract}
Trichobezoar is a rare clinical entity in which a ball of hair accumulates within the alimentary tract. When the tail of the trichobezoar extends into the small intestine, this condition is called Rapunzel syndrome (RS). A 14-year-old female presented with pain abdomen and vomiting for 2 weeks, and a history of trichotillomania and trichophagia, and an epigastric lump. A contrast enhanced computerized tomography (CECT) of the abdomen showed a grossly distended stomach with a heterogeneous mass containing trapped air with underlying normal mucosa suggestive of trichobezoar, with its tail extending into the proximal jejunum suggestive of RS. During laparotomy, a giant trichobezoar was seen in the stomach with its tail extending beyond the duodenum into the proximal jejunum. The entire specimen was delivered out intact. On follow up, she has no surgical complications, and was on behaviour therapy. Trichobezoars form when ingested hair strands become retained in the folds of the gastric mucosa and becomes entangled, forming a ball too large to exit the stomach. Trichotillomania and trichophagia are seen in many of these patients. Patients present with abdominal pain, vomiting, gastric outlet obstruction, and an epigastric mass. In the case of RS, complete removal without breakage and distal migration is important. RS should be considered as a differential diagnosis in a young girl with abdominal pain, vomiting, anaemia and upper abdominal lump. Early diagnosis prevents complications. Surgical removal is treatment of choice. Trichobezoar often coexists with psychiatric illness. Psychiatric evaluation, counselling and treatment are helpful in preventing recurrence.
\end{abstract}

Keywords: RS, Trichobezoar, Trichotillomania, Trichophagia

\section{INTRODUCTION}

Trichobezoar, which was first described by Baudomont in 1779 , is a rare clinical entity in which a ball of hair accumulates within the alimentary tract. It is more common to find this problem in young patients with psychiatric issues, more frequently in girls than boys. ${ }^{1}$

When the tail of the trichobezoar extends into the small intestine, this condition is given the name - Rapunzel syndrome (RS) because of the resemblance of this tail to the hair of Rapunzel, a Grimm Brothers fairy tale princess locked up inside a tower, who uses her long, golden hair to permit her young prince to climb up to her window and rescue her. ${ }^{2}$

RS was first described in the literature by Vaughan et al in which a dense compact mass of hair (trichobezoar) was found in stomach with extension into intestine through duodenum in patients with a history of psychiatric disord er. ${ }^{1}$

The presentation of RS spans a wide spectrum, varying from an asymptomatic state to lump abdomen, gastrointestinal ulceration, obstruction or even perforation in young psychiatric patients. ${ }^{3}$ 
In this report, we present one such unusual case of RS which is rarely reported in the literature.

\section{CASE REPORT}

A 14-year-old female presented to the surgery emergency with complaints of pain in the upper abdomen for the last 2 weeks, and multiple episodes of vomiting for 10 days. A careful history revealed a habit of pulling out her hair (trichotillomania) and eating it (trichophagia) since past 2 years, but they however denied any history of known psychiatric illness. On clinical examination, she was pale and malnourished. Abdominal examination revealed a well-defined, firm, mobile, slightly tender lump occupying the upper abdomen.

An X-ray of the abdomen showed a homogeneous mass in region of stomach, and a CECT of the abdomen showed a grossly distended stomach with a heterogeneous mass containing trapped air with underlying normal mucosa suggestive of trichobezoar, with its tail extending into the proximal jejunum (Figure 1 and 2). On upper gastrointestinal endoscopy, a big tuft of hair was seen occupying the whole stomach and extending beyond the $2^{\text {nd }}$ part of duodenum, which was suggestive of RS.

After psychiatric consultation, the patient was taken for laparotomy. On gastrotomy, a giant trichobezoar was seen in the stomach with its tail extending beyond the duodenum into the proximal jejunum. The entire specimen was delivered out carefully without breakage (Figure 3 and 4). The post-operative period was uneventful, and she was discharged on the $5^{\text {th }}$ postoperative day. The patient was referred to psychiatry for behavioural therapy. On follow up after 1 month, she has no surgical complications, was on high protein diet for nutritional build up, and on behaviour therapy and counselling for trichotillomania and trichophagia.

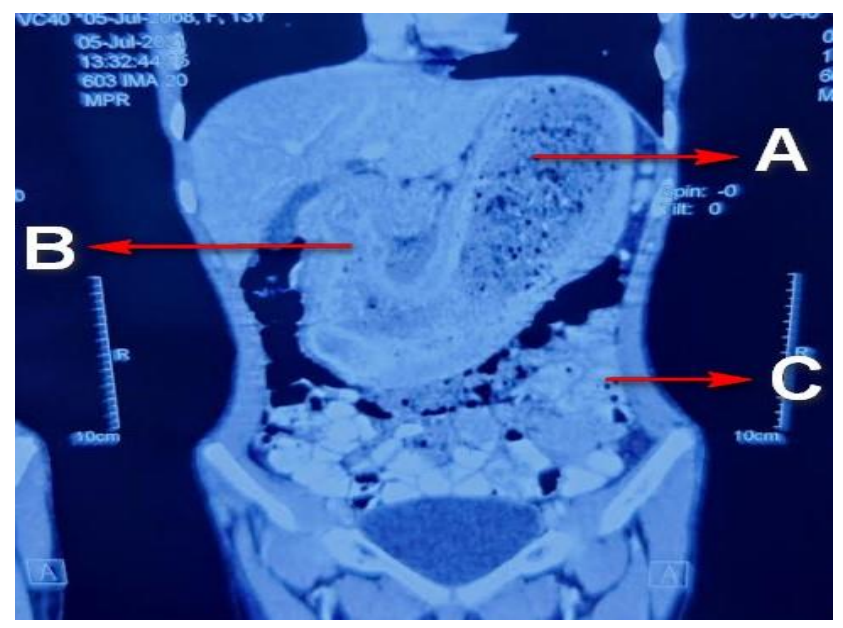

Figure 1: CECT scan of the abdomen-a sagittal section of a hugely distended stomach (A), duodenum (B), and proximal jejunum (C), containing a low attenuating heterogeneous mass containing trapped air, with oral contrast most prominent at its margins, suggestive of a trichobezoar.

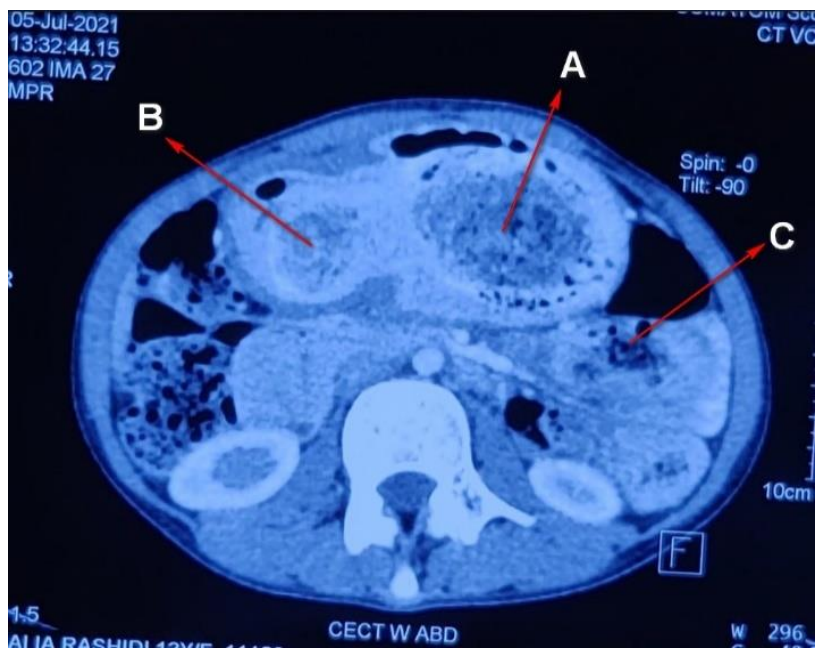

Figure 2: CECT scan of the abdomen-a coronal section showing trichobezoar from stomach (A), extending into the duodenum $(B)$ and proximal jejunum (C).

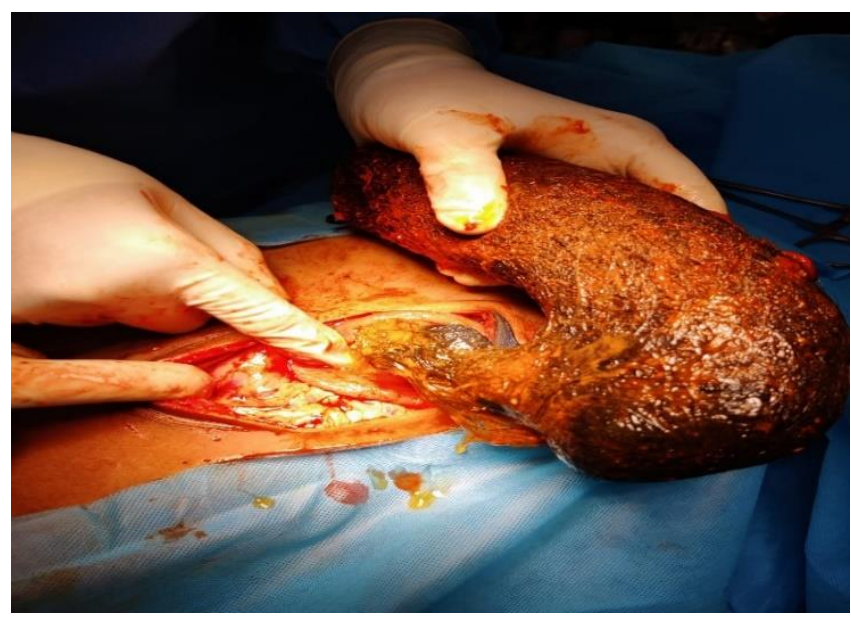

Figure 3: Intra-operative photograph of extraction of the huge trichobezoar through the gastrotomy incision.



Figure 4: The extracted trichobezoar with the long tail which reached up to the proximal jejunum. 


\section{DISCUSSION}

A bezoar is an agglomeration of food or foreign material which accumulates and remains within the gastrointestinal tract. Bezoars are typically either phytobezoars (composed of indigestible vegetable or fruit fibres), trichobezoars (composed of conglomeration of ingested hair), lactobezoars (composed of milk protein), or pharmacobezoars (composed of concretions of various medications). ${ }^{4}$ Trichobezoars form when ingested hair strands become retained in the folds of the gastric mucosa, escaping gastric peristaltic propulsion owing to their slippery surface. More hair becomes entangled by peristalsis, forming a ball too large to exit the stomach and causing gastric atony owing to its large size., Trichotillomania, a compulsive desire to pull out one's own hair, and trichophagia are seen in many of these patients. $^{7}$ This condition is predominantly observed in adolescents with underlying psychiatric disorder, more frequently in girls than boys. 8,9

The name Rapunzel originates from the Brothers Grimm fairy tale of a pretty princess locked inside a tower, who uses her long, golden hair to permit her young prince to climb up to her window and rescue her. ${ }^{2}$ In RS, the trichobezoar extends through the pylorus into the small intestine. Fewer than a hundred cases of RS have been reported in the literature since the initial description in 1968..$^{1,10,11}$

Patients present with abdominal pain (37\%), nausea and vomiting $(33.3 \%)$, gastric outlet obstruction $(25.9 \%)$ and peritonitis $(18.3 \%)$, and the less common ones are weight loss $(7.4 \%)$, anorexia, haematemesis and intussusceptions $(7.4 \%){ }^{12}$ They may also present with complications like obstructive jaundice, small bowel obstruction, pancreatitis, or gastric ulcer. ${ }^{13}$ On clinical examination, a well-defined abdominal mass that is smooth, firm and mobile will be felt in the epigastric region. Halitosis and patchy alopecia may also be noted in these patients. ${ }^{14}$ Often patients coexist with learning disabilities or psychiatric illness. ${ }^{7}$

Plain abdominal radiographs often serve as the initial imaging modality, showing either an inhomogeneous mass or filling defect in the region of the stomach. A barium meal may demonstrate a filling defect in the stomach and confirm the diagnosis. Abdominal ultrasound scanning might demonstrate increased echogenicity, with a marked acoustic shadow due to intermixed hair and food, and CT imaging might show a low attenuating heterogenous mass containing trapped air, with oral contrast most prominent at its margins. ${ }^{15,16}$ Upper GI endoscopy, however, remains the gold standard for diagnosis. ${ }^{17,18}$

The goals of bezoar treatment are the removal of the bezoar and the prevention of recurrence by addressing the underlying psychiatric/emotional cause. ${ }^{18}$ Non-surgical extraction by endoscopy or dissolution by Papain syrup often fails. ${ }^{19}$ As the bezoars are usually too large for dissolution and retrieval, and fragmentation is often impossible owing to size, density and hardness, even with specialised instruments. ${ }^{17,20}$ Endoscopic fragmentation can also lead to distal migration and small bowel obstruction. $^{21}$ A novel laparoscopic-assisted technique using a wound retractor has also been described to improve access and reduce operative time and complications. $^{22}$

In the case of RS, complete removal without breakage and distal migration emphasises the importance of adequate exposure, as well as the limitations of endoscopic management. In surgical management of RS, laparotomy appears more clearly defined, as the bezoar extends beyond the pylorus and because of the risk of incomplete removal. Careful manipulation of the jejunum is required to ensure complete removal of the tail without perforation or breakage.

A comprehensive and long-term psychiatric follow-up is needed in all cases as late relapse is possible. Apart from behaviour therapy, pharmacotherapy may be needed in recurrent or resistant cases. ${ }^{23}$

\section{CONCLUSION}

RS should be considered as a differential diagnosis in a young girl presenting with abdominal pain, vomiting, anaemia and upper abdominal lump. Early diagnosis can prevent complications. Surgical removal at laparotomy or laparoscopy is the treatment of choice. If small, they may be removed endoscopically. As trichobezoar often coexists with psychiatric illness, psychiatric evaluation, counselling and treatment are helpful in preventing recurrence.

\section{Funding: No funding sources \\ Conflict of interest: None declared \\ Ethical approval: Not required}

\section{REFERENCES}

1. Vaughan ED Jr, Sawyers JL, Scott HW Jr. The Rapunzel syndrome. An unusual complication of intestinal bezoar. Surgery. 1968;63(2):339-43.

2. Grimm Brothers: Rapunzel. Translated by GodwinJones R. Richmond, Virginia Commonwealth University Department of Foreign Languages. 19941999.

3. Naik S, Gupta V, Naik S, Rangole A, Chaudhary AK, Jain $P$ et al. Rapunzel syndrome reviewed and redefined. Dig Surg. 2007;24(3):157-61.

4. Sanders MK. Bezoars: From Mystical Charms to Medical and Nutritional Management. Practical Gastroenterolo. 2004:28;37-50.

5. Pace AM, Fearne C. Trichobezoar in a 13-year-old male: A case report and review of literature. Malta Med J. 2003;15:39-40. 
6. Deslypere JP, Praet M, Verdonk G. An unusual case of the trichobezoar: the Rapunzel syndrome. Am J Gastroenterol. 1982;77(7):467-70.

7. Schlosser S, Black DW, Blum N, Goldstein RB. The demography, phenomenology, and family history of 22 persons with compulsive hair pulling. Ann Clin Psychiatry. 1994;6(3):147-52.

8. Western C, Bokhari S, Gould S. Rapunzel syndrome: a case report and review. J Gastrointest Surg. 2008;12(9):1612-4.

9. Bhatia MS, Singhal PK, Rastogi V, Dhar NK, Nigam VR, Taneja SB. Clinical profile of trichotillomania. J Indian Med Assoc. 1991;89(5):137-9.

10. Naik S, Gupta V, Naik S, Rangole A, Chaudhary AK, Jain P, Sharma AK. Rapunzel syndrome reviewed and redefined. Dig Surg. 2007;24(3):15761.

11. Kwong WT, Kalmaz D. A modern form of Rapunzel syndrome: trichobezoar composed of synthetic hair extensions. Clin Gastroenterol Hepatol. 2014;12(5):A33-4.

12. Wang Z, Cao F, Liu D, Fang Y, Li F. The diagnosis and treatment of Rapunzel syndrome. Acta Radiol Open. 2016;5(11):2058460115627660.

13. Ullah W, Saleem K, Ahmad E, Anwer F. Rapunzel syndrome: a rare cause of hypoproteinaemia and review of literature. BMJ Case Rep. 2016;2016:bcr2016216600.

14. Sah DE, Koo J, Price VH. Trichotillomania. Dermatol Ther. 2008;21(1):13-21.

15. Newman B, Girdany BR. Gastric trichobezoarssonographic and computed tomographic appearance. Pediatr Radiol. 1990;20(7):526-7.

16. West WM, Duncan ND. CT appearances of the Rapunzel syndrome: an unusual form of bezoar and gastrointestinal obstruction. Pediatr Radiol. 1998;28(5):315-6.

17. Wang YG, Seitz U, Li ZL, Soehendra N, Qiao XA. Endoscopic management of huge bezoars. Endoscopy. 1998;30(4):371-4.

18. Gonuguntla V, Joshi DD. Rapunzel syndrome: a comprehensive review of an unusual case of trichobezoar. Clin Med Res. 2009;7(3):99-102.

19. Soufi M, Benamr S, Belhassan M, Massrouri R, Ouazzani H, Chad B. Giant trichobezoar of duodenojejunal flexure: a rare entity. Saudi J Gastroenterol. 2010;16(3):215-7.

20. Gorter RR, Kneepkens CM, Mattens EC, Aronson DC, Heij HA. Management of trichobezoar: case report and literature review. Pediatr Surg Int. 2010;26(5):457-63.

21. Fallon SC, Slater BJ, Larimer EL, Brandt ML, Lopez ME. The surgical management of Rapunzel syndrome: a case series and literature review. J Pediatr Surg. 2013;48(4):830-4.

22. Tudor EC, Clark MC. Laparoscopic-assisted removal of gastric trichobezoar; a novel technique to reduce operative complications and time. J Pediatr Surg. 2013;48(3):e13-5.

23. Franklin ME, Edson AL, Ledley DA, Cahill SP. Behavior therapy for pediatric trichotillomania: a randomized controlled trial. J Am Acad Child Adolesc Psychiatry. 2011;50(8):763-71.

Cite this article as: Manchikanti D, Aggarwal M, Thomas S, Arsia A, Pusuluri R, Kumar S. Rapunzel syndrome: an uncommon tale of a long hairy tail-case report and review of literature. Int Surg J

2021;8:3463-6. 